\title{
Article \\ Effect of Accommodation on Peripheral Higher Order Aberrations
}

\author{
Kishor Sapkota (D), Jessica Gomes (D) and Sandra Franco *(D) \\ Centre of Physics, Campus de Gualtar, University of Minho, 4710-057 Braga, Portugal; \\ kishorsapkota@gmail.com (K.S.); jessicarafamg@gmail.com (J.G.) \\ * Correspondence: sfranco@fisica.uminho.pt
}

Citation: Sapkota, K.; Gomes, J.; Franco, S. Effect of Accommodation on Peripheral Higher Order

Aberrations. Photonics 2022, 9, 64 https://doi.org/10.3390/ photonics 9020064

Received: 25 November 2021

Accepted: 22 January 2022

Published: 26 January 2022

Publisher's Note: MDPI stays neutral with regard to jurisdictional claims in published maps and institutional affiliations.

Copyright: () 2022 by the authors Licensee MDPI, Basel, Switzerland. This article is an open access article distributed under the terms and conditions of the Creative Commons Attribution (CC BY) license (https:// creativecommons.org/licenses/by/ $4.0 /)$.

\begin{abstract}
Knowledge of the effect of accommodation on image quality of peripheral retina is crucial for better understanding of the visual system, but only a few studies have been carried out in this area. This study was designed to evaluate the effect of accommodation on higher order aberrations from third to sixth Zernike polynomials in central and peripheral retina up to $23^{\circ}$ off-axis. We used a Hartmann-Shack aberrometer to measure Zernike coefficients with both accommodated and non-accommodated eyes of 15 healthy subjects. Each Zernike coefficient, total higher order aberrations, spherical aberrations and astigmatism were compared between accommodated and non-accommodated status. Additionally, aberrations in the central retina were compared with the peripheral retina. Accommodation induced significant changes in the Zernike coefficients of vertical pentafoil $C_{5}^{-5}$ and secondary vertical tetrafoil $C_{6}^{-4}$ in central retina, secondary vertical astigmatism $\mathrm{C}_{4}^{-2}$ on $23^{\circ}$ of temporal retina, secondary vertical tetrafoil $C_{6}^{-4}$ and tertiary vertical astigmatism $C_{6}^{-2}$ on $10^{\circ}$ of nasal retina, secondary vertical trefoil $C_{5}^{-3}$ and secondary vertical tetrafoil $C_{6}^{-4}$ on $23^{\circ}$ of nasal retina, and horizontal tetrafoil $C_{4}^{4}$, and secondary horizontal tetrafoil $C_{6}^{4}$ on $23^{\circ}$ of inferior retina $(p<0.05)$. Total higher order aberration was lower in each retinal area examined with accommodation, but it was statistically significant only on $23^{\circ}$ temporal retina and $11.5^{\circ}$ and $23^{\circ}$ of superior retina $(p<0.05)$. Spherical aberration decreased with accommodation on $23^{\circ}$ temporal retina $(p=0.036)$. Astigmatism was similar in non-accommodated and accommodated eyes. Overall, accommodation affected higher order aberration (HOA) asymmetrically in different peripheral retinal areas.
\end{abstract}

Keywords: higher order aberration; accommodation; peripheral retina

\section{Introduction}

Aberrometers have been widely used to measure the optical quality of the visual system. The wavefront sensor of the instrument measures Zernike polynomials, which are helpful to monitor the optical condition of the eye. Moreover, aberrometers with adaptive optics can be used to develop a model to show how a human eye behaves after correction of higher order aberrations. Commercially available aberrometers can measure low and high order aberrations of the central optical system and, with some modifications, can also measure peripheral aberrations [1,2].

Visual resolution is poor in the peripheral retina because of the low density of the photo-receptor cell-cones [3]. Furthermore, optical quality in the off-central retina is degraded by astigmatism, coma and other higher order aberrations [4]. Peripheral vision is important for everybody, but particularly for those who have lost foveal vision. On-screen experiments have underestimated the role of peripheral vision in the real-world search, but peripheral pre-processing of a target has a much higher role in identifying objects in comparison to the central vision [5]. In addition, recent studies have found the possible link between myopia development and the relative peripheral refraction [4]. These factors trigger the need for more studies on peripheral aberrations. 
Accommodation is the ability of a crystalline lens to increase its converging power by increasing surface curvature and decreasing equitorial diameter to make a clear image on retina when the viewing object is located in a closer distance. Accommodation has an important role in optical quality of the eye, particularly to focus on near objects. Several studies have been carried out on the effect of accommodation on aberrations on the foveal fixation. On-axis higher order aberrations change significantly with changes in accommodation in children [6] and adults [7] and this effect is correlated with the degree of accommodation [6]. Primarily, this may be due to the change in shape of the crystalline lens during accommodation; however, there might be some role of cornea because of the changes in corneal elevation or the cyclotorsional eye movements during accommodation [8]. A previous study did not find any difference in the accommodative response with or without higher-order aberrations but suggested that higher-order aberrations can provide the sign of defocus for accommodation [9].

Several on-axis studies have shown that spherical aberration shifts to negative direction or becomes more negative with accommodation $[7,10,11]$. Li et al. found changes in total higher order aberrations (HOA) with accommodation in normal adult subjects, and this effect was more prominent in spherical aberrations [11]. No significant change was found in coma with accommodation [7,12]. Scott and Atchison used a modified HartmannShack sensor to measure aberrations in the temporal and nasal visual fields and found that HOAs are greater on a nasal visual field [13]. They found third order aberration as the major contributor on the total HOA.

Only a few studies have been carried out on peripheral higher order aberrations and accommodation, and most of them are offered only in one meridian, either vertical or horizontal $[2,13,14]$. Thus, this study was designed to assess the role of accommodation on HOA on peripheral retina in horizontal as well as vertical meridians with a laboratory Hartmann-Shack aberrometer. Zernike coefficients, total root-mean-square (RMS) of coefficients of third to sixth order, higher order astigmatism (fourth and sixth order) and spherical aberration (fourth and sixth order) were compared between eyes with non-accommodated and accommodated states. The variation of values from central to peripheral retina was also determined.

\section{Materials and Methods}

This was a cross-sectional study conducted at the University of Minho, Portugal. Healthy subjects with the best corrected visual acuity of $6 / 6$ or better and without any accommodative dysfunction, ocular pathology and previous ocular surgery were included. The sample size of this study was similar to the previous studies conducted on central or peripheral higher order aberration $[7,13,14]$. An optometric exam was performed in all subjects to ensure the selection criteria and to assess visual acuity and refractive state. Amplitude of accommodation was measured by Sheard's method.

Written informed consent was obtained after explanation of consequences of the study. This study was approved by the Ethical Sub-committee of the Life and Health Science of University of Minho and followed the tenets of the Declaration of Helsinki.

Ocular aberrations were measured with an in-house Hartmann-Shack aberrometer with $1280 \times 1024$ resolution and $39 \times 31$ lenslet working at $15 \mathrm{~Hz}$ frequency as described in an earlier study [15]. A super luminescent diode of $12 \mu \mathrm{W}$ generated the optical beam of $830 \mathrm{~nm}$. The Hartmann-Shack sensor has been widely used in measuring optical quality of eye [2].

In each subject, aberrations of right eyes were measured [4]. The fellow eye was occluded during the process and the data were collected over refractive correction [14]. The fixation target was a black cross over white background, and it was presented on a monitor. The configuration of the optical system allows a target vergence close to zero in the ocular surface, simulating infinity and causing negligible accommodative demand. The position of the target was controlled by software and could be moved to different positions (11.5 degrees change with single step movement) across the visual field. 
The position of the source of infrared light was fixed. Firstly, the source of infrared and the cross (the target) were overlapped to obtain the data on central retina. Then, the cross was moved to 11.5 degrees and then 23 degrees off-axis in the temporal and nasal as well as superior and inferior visual fields to obtain aberration data of temporal, nasal, superior and inferior retina (Figure 1). The amount of eccentricity was limited within 23 degrees on each direction because we were unable to obtain aberration data with further eccentricity on some subjects in our setup. After a few minutes, the process was repeated with minus $2.50 \mathrm{D}$ lens placed $12 \mathrm{~mm}$ in front of the eye on a trial frame (2.43 D of accommodative stimuli) to obtain the aberration data on the central as well as peripheral retinal areas. This small amount of accommodation stimulus was presented so that subjects with a low amplitude level of accommodation could also be assessed. Moreover, $2.50 \mathrm{D}$ is the accommodative demand needed for daily near vision tasks, which is usually at $40-50 \mathrm{~cm}$.

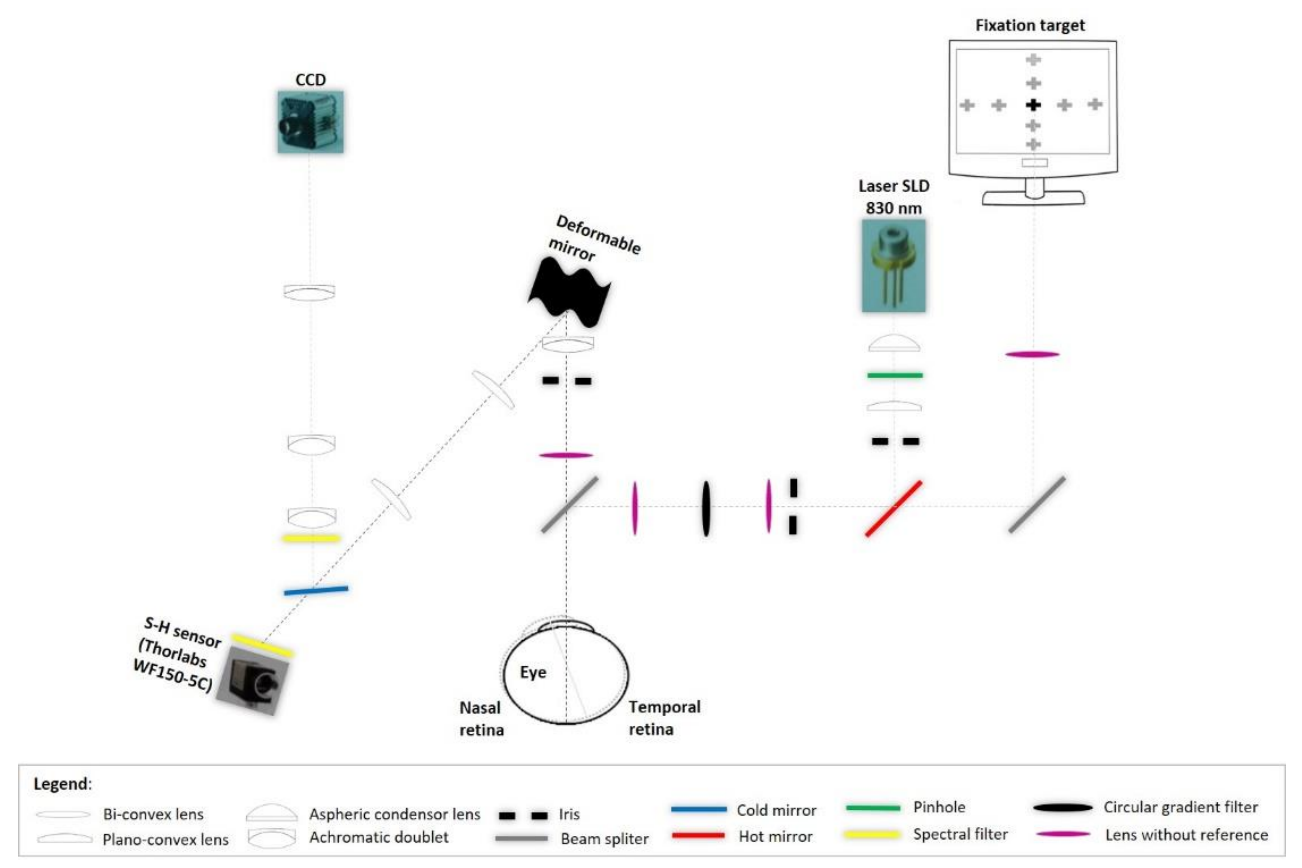

Figure 1. Simplified schematic representation of the experimental procedure. A laser super luminescent diode (SLD) was used to generate a point source, which reflects on retina and propagates out of the eye; the wavefront being sampled at the sensor. A fixation target was presented on a monitor. The configuration of the optical system allows a target vergence close to zero on the ocular surface and that angular deviation in relation to the eye was characterized by the angular amplification of the optical system between the monitor and the eye. The position of the target was controlled by software and could be moved to different positions.

The position of the measuring system was always maintained constant, and the subject was asked to fix the target moving his eye to the different fixation positions, maintaining the head fixed; the subject's head was stabilized on the chinrest. Before the measurement, the subjects were advised to blink to provide a smooth tear surface. However, they were suggested not to blink during the measurement because blinking may cause a sudden change in the aberrations $[16,17]$.

All the Zernike coefficients, $C_{n}^{m}$ where the indices $\mathrm{n}$ and $\mathrm{m}$ represent the radial order and the azimuthal frequency, from 3rd order to 6th order (6th coefficient to 27th coefficient) were collected from the central and peripheral retina and saved. The Hartmann-Shack aberrometer is connected to a computer, which contains purpose-developed software that provides raw values of the Zernike coefficients up to the sixth order. Baseline values, i.e., the aberrations of the optical system itself, were initially measured and then subtracted from the respective coefficients before using them in the analysis. During the examination, 
wavefront image and signal of each Zernike coefficient were monitored and if any incomplete wavefront image or abnormal signals were observed, the corresponding data were discarded and the process was repeated.

The spherical equivalent was calculated using the following formula:

$$
M=\frac{-4 \sqrt{3} C_{2}^{0}}{r^{2}}
$$

where $C_{2}^{0}$ is the defocus and $r$ is the pupil radius.

The analysis was conducted with $4.5 \mathrm{~mm}$ of pupil diameter, and before the measurements it was ensured that all subjects had a pupil size greater than this value in the mesopic conditions in which the procedure was performed.

During the measures with accommodation, as negative lenses were placed in front of the eye, the defocus corresponding to each lens in the eye plane was subtracted from the total defocus, in order to obtain the defocus of the subjects' eye. The respective spherical equivalent was calculated and then obtained the accommodative response of the subjects. The average change of accommodation was $1.42 \mathrm{D}$ in the central retina. The changes in accommodation on different central and peripheral retinal areas are presented in Table 1.

Table 1. Average changes in accommodation on different central and peripheral fixations.

\begin{tabular}{cccc}
\hline & $\mathbf{0}^{\circ}$ & $\mathbf{1 1 . 5}^{\circ}$ & $\mathbf{2 3}^{\circ}$ \\
\hline Centre & $1.42 \pm 1.72 \mathrm{D}$ & & \\
Temporal & & $1.40 \pm 1.67 \mathrm{D}$ & $1.49 \pm 1.02 \mathrm{D}$ \\
Nasal & & $2.08 \pm 1.27 \mathrm{D}$ & $1.97 \pm 1.23 \mathrm{D}$ \\
Superior & $2.12 \pm 1.32 \mathrm{D}$ & $1.59 \pm 2.01 \mathrm{D}$ \\
Inferior & $1.78 \pm 1.54 \mathrm{D}$ & $1.48 \pm 1.55 \mathrm{D}$ \\
\hline
\end{tabular}

From the Zernike coefficients, total HOA was calculated applying the following formula:

$$
\mathrm{HOA}=\sum_{i=6}^{i=27} \sqrt{(\mathrm{C} i)^{2}},
$$

where $C i$ represents $i$ th Zernike coefficient.

Higher order astigmatism was calculated as the square root of sum of squares of $\mathrm{C}_{4}^{-2}$, $C_{4}^{2}, C_{6}^{-2}$ and $C_{6}^{2}$. Similarly, spherical aberration was calculated as the square root of the sum of squares of $C_{4}^{0}$ and $C_{6}^{0}$.

IBM Statistics SPSS 23 was applied to assess the difference of aberrations in different positions and to compare them before and after stimulating accommodation. Depending upon the distribution of the variables, paired sample $t$-Test or Wilcoxon Signed Ranks test and repeated measures of ANOVA were applied to check any difference between variables. $p$ value of less than 0.05 was considered as statistically significant.

\section{Results}

Fifteen young and healthy subjects were included in this study and nine $(60 \%)$ were females. The mean age of the participants was $25.0 \pm 4.7$ years with range 21 to 36 years. Mean spherical equivalent refraction was $-0.20 \mathrm{D} \pm 1.13 \mathrm{D}$ with astigmatism less than 1.25 $\mathrm{D}$ and the mean amplitude of accommodation was $8.08 \mathrm{D} \pm 2.04 \mathrm{D}$. None of the participants had an accommodative dysfunction.

\subsection{Central vs. Peripheral Aberrations with Non-Accommodated Eyes}

All the Zernike coefficients except $C_{6}^{-4}$ were similar in central and peripheral retina on naked eyes. In non-accommodated eyes, there was no statistically significant difference in total HOA in central and peripheral retina $(p=0.288)$, but there was a significant difference in higher order astigmatism in different areas of the retina $(F(3.661,51.259)=2.670$, $p=0.047)$. On post hoc analysis, astigmatism was higher on $11.5^{\circ}(p=0.038)$ and $23^{\circ}$ 
superior retina $(p=0.005)$ in comparison to the central retina. There was a difference in spherical aberration in different retinal areas in non-accommodated state $(\mathrm{F}(8,112)=2.178$, $p=0.034)$. In comparison to central retina, spherical aberration was higher on superior retina (both on $11.5^{\circ}$ and $23^{\circ}$ off-axis), but there was not a significant difference with other peripheral retinal areas $(p>0.05)$.

\subsection{Central vs. Peripheral Aberrations with Accommodation}

No statistically significant difference was obtained between central and peripheral Zernike coefficients when the eye was stimulated with the $-2.50 \mathrm{D}$ lens $(p>0.05)$. There was no significant difference in total $\operatorname{HOA}(\mathrm{F}(1.620,22.682)=0.793, p=0.440)$ and spherical aberrations $(\mathrm{F}(2.661,37.251)=1.442, p=0.248)$ in central and peripheral retinal areas in the accommodated eye. However, astigmatism was higher on $23^{\circ}$ nasal retina $(p=0.049)$ and $23^{\circ}$ inferior retina $(p=0.033)$ in comparison to the central area with accommodation.

\subsection{Accommodated vs. Non-Accommodated Eyes}

Table 2 presents the variation in Zernike coefficients from third to sixth order due to accommodation in the central and peripheral retina. Most of the Zernike coefficients were similar with and without accommodation; however, there was a statistically significant difference in some Zernike coefficients with accommodation. In the central retina, vertical pentafoil $\left(C_{5}^{-5}\right)$ and secondary vertical tetrafoil $\left(C_{6}^{-4}\right)$ were affected by accommodation. There was no change in Zernike coefficients in the temporal retina with $11.5^{\circ}$ eccentricity but with $23^{\circ}$ eccentricity, secondary vertical astigmatism $\left(C_{4}^{-2}\right)$ was affected $(p=0.043)$ by accommodation. Secondary vertical tetrafoil $\left(\mathrm{C}_{6}^{-4}\right)$ and tertiary vertical astigmatism $\left(C_{6}^{-2}\right)$ on $11.5^{\circ}$ nasal retina and secondary vertical trefoil $\left(C_{5}^{-3}\right)$ and secondary vertical tetrafoil $\left(C_{6}^{-4}\right)$ on $23^{\circ}$ nasal retina were different. There was no difference in any Zernike coefficients in the superior retina, but horizontal tetrafoil $\left(C_{4}^{4}\right)$, and secondary horizontal tetrafoil $\left(C_{6}^{4}\right)$ were different on $23^{\circ}$ inferior retina. The difference in Zernike coefficients, which were affected by accommodation are presented in Figure 2.

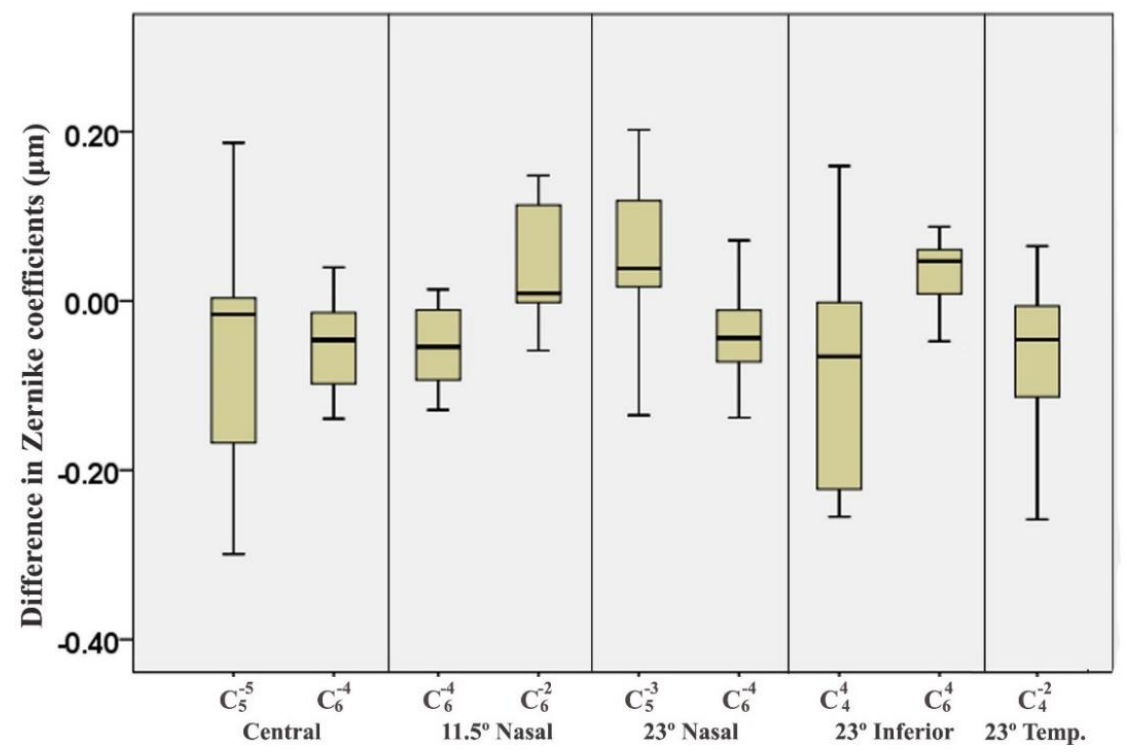

Figure 2. Box plot of the mean difference (non-accommodated-accommodated state) of Zernike coefficients, which were affected by accommodation.

Figure 3 presents the difference in RMS of total HOA, spherical aberrations and astigmatism in central and peripheral retina with relaxed and accommodated status. Total HOA was lower in each retinal corresponding area with accommodation; however, the differences were statistically significant only in $23^{\circ}$ temporal $(p=0.006), 11.5^{\circ}$ superior $(p=0.031)$ 
and $23^{\circ}$ superior $(p=0.046)$ retina. There was no significant difference in higher order astigmatism with and without accommodation in any respective retinal areas $(p>0.05)$. Spherical aberration was found to be decreased with accommodation on $23^{\circ}$ temporal retina $(p=0.036)$, but it was similar in all the other retinal areas.

Table 2. Mean difference of the higher order Zernike coefficients $(\mu \mathrm{m})$ between non-accommodated and accommodated status in central and peripheral retina ${ }^{\mathrm{a}}$.

\begin{tabular}{|c|c|c|c|c|c|c|c|c|c|}
\hline & Central & $\begin{array}{c}11.5^{\circ} \\
\text { Temporal }\end{array}$ & $23^{\circ}$ Temporal & $11.5^{\circ}$ Nasal & $23^{\circ}$ Nasal & $\begin{array}{c}11.5^{\circ} \\
\text { Superior }\end{array}$ & $\begin{array}{c}23^{\circ} \\
\text { Superior }\end{array}$ & $\begin{array}{c}11.5^{\circ} \\
\text { Inferior }\end{array}$ & $23^{\circ}$ Inferior \\
\hline $\mathrm{C}_{3}^{-3}$ & -0.1533 & -0.1504 & 0.1541 & -0.0513 & -0.0325 & 0.0450 & 0.1266 & 0.0470 & -0.0401 \\
\hline$C_{3}^{-1}$ & 0.2130 & 0.0577 & 0.1385 & 0.0827 & -0.1842 & -0.0660 & -0.2028 & -0.1879 & 0.0832 \\
\hline$C_{3}^{1}$ & -0.1713 & -0.0430 & -0.0426 & 0.1490 & 0.0189 & -0.0854 & 0.0285 & -0.0707 & -0.2057 \\
\hline$C_{3}^{3}$ & 0.0530 & -0.1025 & -0.1386 & 0.1041 & 0.1925 & 0.0849 & 0.1560 & -0.0471 & 0.0544 \\
\hline$C_{4}^{-4}$ & 0.0503 & 0.0450 & -0.0858 & 0.0810 & 0.0000 & -0.0800 & -0.0950 & -0.0283 & -0.0450 \\
\hline$C_{4}^{-2}$ & -0.0540 & -0.0192 & $-0.0636^{p=0.043}$ & -0.0915 & -0.0681 & -0.0543 & -0.0461 & -0.0308 & -0.0643 \\
\hline$C_{4}^{0}$ & 0.0944 & -0.0210 & -0.0020 & 0.0151 & -0.0270 & 0.0906 & -0.0509 & -0.0617 & -0.1091 \\
\hline$C_{4}^{2}$ & -0.0409 & 0.0508 & 0.1425 & 0.0795 & 0.0372 & -0.0449 & 0.0948 & 0.1059 & 0.1727 \\
\hline$C_{4}^{4}$ & -0.0340 & 0.0293 & -0.0939 & -0.0347 & -0.0420 & 0.0014 & -0.0509 & -0.1214 & $-0.1156^{p}=0.026$ \\
\hline$C_{5}^{-5}$ & $-0.0678^{p=0.013}$ & -0.0545 & -0.0192 & -0.0502 & -0.0183 & -0.0336 & 0.0199 & 0.0076 & -0.0131 \\
\hline$C_{5}^{-3}$ & 0.0631 & 0.0485 & 0.0053 & 0.1066 & $0.0737^{p}=0.025$ & 0.0564 & -0.0147 & -0.0199 & 0.0199 \\
\hline$C_{5}^{-1}$ & -0.0304 & -0.0160 & -0.0321 & -0.0380 & 0.0238 & -0.0142 & 0.0801 & 0.0865 & 0.0096 \\
\hline$C_{5}^{1}$ & 0.0756 & 0.0448 & 0.0298 & -0.0551 & -0.0395 & -0.0053 & -0.0729 & 0.0154 & 0.0676 \\
\hline$C_{5}^{3}$ & -0.0228 & 0.0201 & 0.0101 & -0.0150 & -0.0438 & -0.0139 & -0.0016 & -0.0073 & -0.0180 \\
\hline$C_{5}^{5}$ & 0.0430 & -0.0207 & -0.0423 & -0.0425 & -0.0345 & 0.0321 & -0.0390 & 0.0476 & 0.0269 \\
\hline$C_{6}^{-6}$ & 0.0230 & -0.0151 & -0.0268 & 0.0171 & -0.0212 & -0.0006 & -0.0040 & -0.0135 & 0.0034 \\
\hline$C_{6}^{-6}$ & $-0.0555^{p=0.001}$ & 0.0027 & 0.0206 & $-0.0536^{p=0.001}$ & $-0.0417^{p=0.019}$ & 0.0074 & -0.0006 & -0.0154 & -0.0175 \\
\hline$C_{6}^{-2}$ & 0.0248 & 0.0128 & 0.0071 & $0.0436^{p=0.027}$ & 0.0274 & 0.0213 & 0.0127 & 0.0078 & 0.0291 \\
\hline$C_{6}^{0}$ & -0.0276 & -0.0020 & -0.0085 & -0.0101 & -0.0096 & -0.0317 & 0.0115 & 0.0338 & 0.0266 \\
\hline$C_{6}^{2}$ & 0.0291 & -0.0192 & -0.0485 & -0.0146 & 0.0194 & 0.0076 & -0.0053 & -0.0242 & -0.0494 \\
\hline$C_{6}^{4}$ & -0.0249 & 0.0052 & 0.0302 & 0.0117 & 0.0053 & 0.0008 & 0.0076 & 0.0325 & $0.0332^{p=0.040}$ \\
\hline$C_{6}^{0}$ & 0.0036 & 0.0153 & -0.0074 & -0.0009 & -0.0172 & -0.0352 & -0.0269 & -0.0328 & -0.0488 \\
\hline
\end{tabular}

${ }^{a} p$ values are written as superscript of in the statistically significant differences.

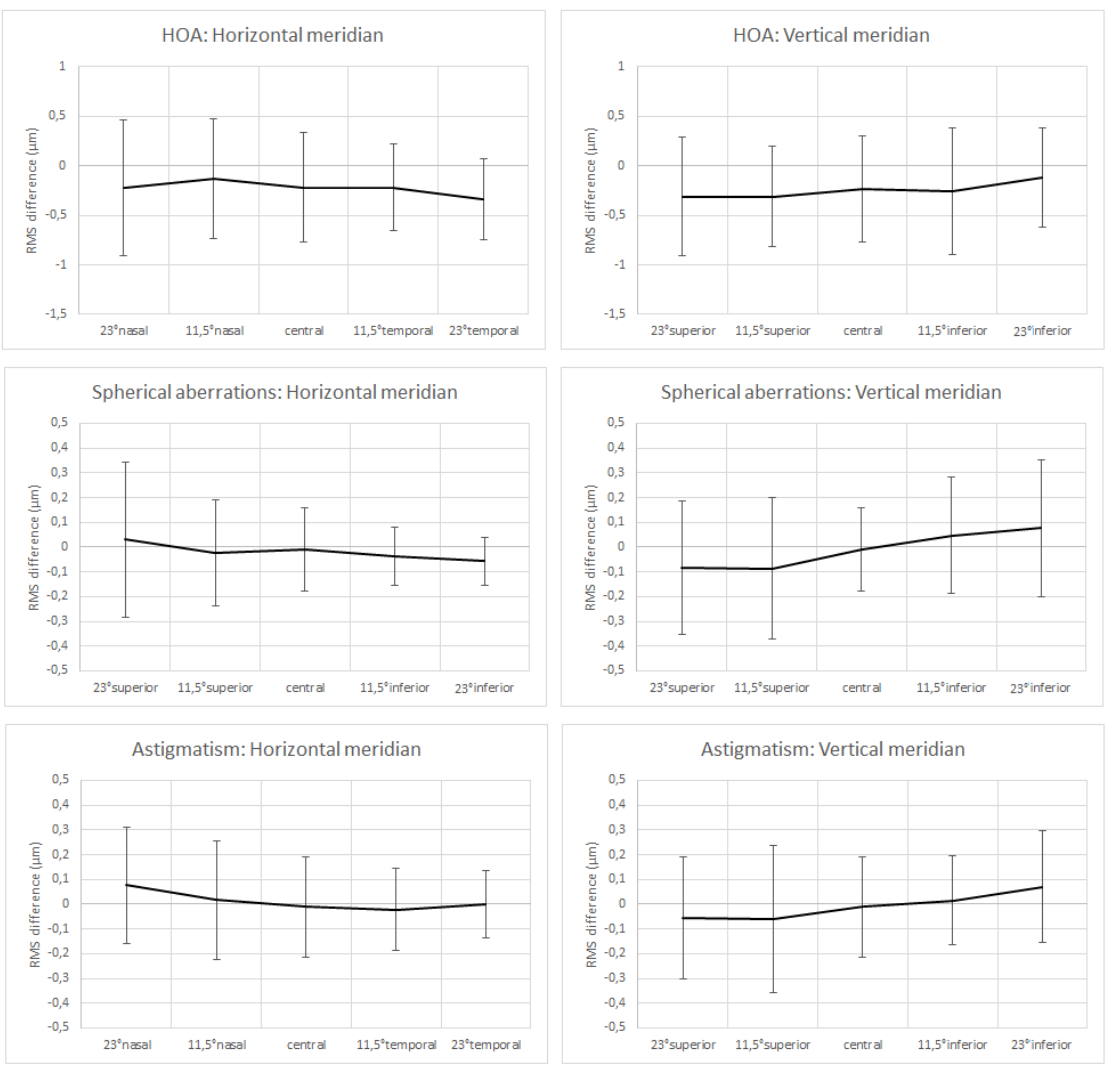

Figure 3. Difference of total HOA, higher order astigmatism and spherical aberrations between relaxed and accommodated states in the central and peripheral retina. Error bars show the standard deviation of each mean value. RMS: root-mean-square, HOA: higher order aberration. 


\section{Discussion}

In this study we determined Zernike coefficients and aberrations of higher orders, including total higher order astigmatism, total spherical aberrations from third to sixth order in naked eyes with accommodation relaxed and with accommodated eyes. Aberrations in central retina were compared with peripheral retina as well as aberrations in different central and peripheral retina in non-accommodated eyes were compared with aberrations in respective retinal areas of accommodated eyes.

There was no difference in central and off-axis Zernike coefficients in the third, fourth and fifth order, but only tetrafoil of the sixth order $\left(C_{6}^{-4}\right)$ was different from the central to periphery retina in relaxed accommodation. Moreover, Zernike coefficients of each order and frequency were similar from central to periphery retina, both vertically and horizontally, in the accommodated eye. This implies that eccentricity up to $23^{\circ}$ does not affect the values of Zernike coefficients, either on non-accommodated eyes or with low level of accommodation in $4.50 \mathrm{~mm}$ pupil. Contrary to these findings, a previous study found that higher order aberrations are greater in the nasal field of view [13]. The authors concluded that third order aberrations are the major contributors of the total HOAs. However, they have applied $6 \mathrm{~mm}$ pupil size and assessed the peripheral HOA only in horizontal meridians [13]. Moreover, they had assessed the aberrations on up to 40 degrees off-axis while it was only up to 23 degrees in the current study. The amount of eccentricity may affect aberrations [14].

This study shows no effect of accommodation in the majority of the Zernike coefficients on the central as well as peripheral retina as most of the values were similar with and without accommodation. This might be due to the small amount of accommodation demand stimulated in the subjects of the current study [7]. All the Zernike coefficients of third order were similar in relaxed and accommodated eyes. Among the fourth order Zernikes, the only significant difference observed was in secondary vertical astigmatism $\left(C_{4}^{-2}\right)$ on $23^{\circ}$ superior retina and horizontal tetrafoil $\left(C_{4}^{4}\right)$ on $23^{\circ}$ inferior retina, in both the cases the negative values were changed into positive values. Similarly, the sixth order Zernike coefficients, which were affected by accommodation, changed their direction from negative to positive after accommodation. Although the differences were statistically significant, the values were very small, and it is not known whether these are clinically significant or not. A small amount of difference may be contributed by the repeatability of the instrument. In contrast to this study, Zhou et al. found a decrease in Zernike coefficient with increasing accommodation and this effect is higher with higher accommodation stimuli [7]. In another study conducted in children, Hughes et al. found that Zernike coefficients change significantly with accommodation and this effect is higher with higher accommodation demand [6]. Unlike our findings, they found large difference in primary $\left(C_{4}^{0}\right)$ and secondary spherical aberrations $\left(C_{6}^{0}\right)$. This might be due to higher amount of accommodation demand and subjects with high amplitude of accommodation in their study. Cheng et al. found a difference in coma with accommodation, which was higher with higher accommodation demand [18].

There was no statistical difference in the total HOA on the nasal retina and superior retina as well as inferior retina in comparison to the central retina, both on nonaccommodated and accommodated eyes. An earlier study where HOAs were evaluated up to $40^{\circ}$ off-axis showed that HOA are larger in the nasal visual field [4]. Thus, the no significant difference in HOA in central and periphery found in the current study may be due to smaller angle of eccentricity. Moreover, in the current study, accommodation reduced the total $\mathrm{HOA}$ in $23^{\circ}$ temporal retina and superior retina but does not affect other areas of the retina. In an earlier study, Radhakrishnan and Charman also did not find any effect of accommodation in HOA [12]. On the one hand, the non-significant difference in HOA on nasal and inferior retina in the current study may be due to the smaller size of pupil used during aberrometry [11]. It is anticipated that the larger the pupil, the greater the aberrations. On the other hand, the small difference or non-significant difference in higher order aberrations with accommodation in the current study may be due to the small 
amount of accommodation stimuli. A lens of only minus two and a half dioptre was used to stimulate accommodation in this study and the changes in accommodation were small (Table 1). Zhou et al. found that only a higher amount of accommodation stimuli affects the higher order aberrations [7]. Similarly, Cheng et al. showed no significant difference in higher order aberrations up to an accommodation demand of $3.00 \mathrm{D}$ [18].

It is interesting to note that astigmatism behaves differently in different retinal areas on non-accommodated eyes. The RMS of fourth and sixth order astigmatism was higher on superior retina in comparison to the central retina, but it was similar on the inferior, nasal and temporal retina. As the anterior corneal surface flattens from central to periphery asymmetrically, corneal asphericity may have some role on variation of higher order astigmatism [19]. However, in the accommodated eye, astigmatism was higher on nasal retina and inferior retina in comparison to the values on central retina. This supports that accommodation changes the direction of astigmatism in eccentric fixations on some areas of the retina, which may be due to the change in shape of crystalline lens becoming more hyperbolic with accommodation [20]. The effect of eye torsion on variation in astigmatism after accommodation is not clear. In contrast to an earlier study, no effect of accommodation was observed in the higher order astigmatism in the central retina. Cheng et al. found change in astigmatism with accommodation; however, the change was very low in comparison to the effect of accommodation in spherical aberration [18]. Again, no difference was observed in respective peripheral retinal areas between relaxed and accommodated eyes. So, this study highlights that a small amount of accommodation does not have an effect on higher order astigmatism in any central or peripheral retina with a $4.50 \mathrm{~mm}$ pupil size. Similar with our findings, Mathur et al. also did not find any effect of accommodation in fourth order astigmatism [21].

Spherical aberration was significantly higher on the superior retina in comparison to the central retina. However, with accommodation, there was no difference in spherical aberration on the central and peripheral retina. This implies that accommodation reduces the disparity of spherical aberration between central and peripheral retina. Unlike our findings, Lundstrom et al. found a slight decrease in spherical aberration in periphery, which was correlated with the angle of eccentricity [22]. It is known that positive spherical aberration is balanced by negative spherical aberration of the crystalline lens [23]. Thus, it was expected that spherical aberrations change to a negative direction with accommodation in all the central and peripheral retina. However, in the current study, there was no change in spherical aberrations with accommodation in any central and peripheral retinal areas except on $23^{\circ}$ temporal retina where accommodation reduced the spherical aberrations. Contrary to the current study, a couple of previous studies found the effect of accommodation on spherical aberration in central fixation $[11,12,18]$. Radhakrishnan and Charman found a decrease in spherical aberration with accommodation in younger subjects [12]. Similarly, Li et al. found a significant change in spherical aberration in central fixation [11]. Cheng et al. found that spherical aberration in the central fixation is the main higher order aberration affected by accommodation [18]. The contrasting findings of the current study may be due to the fact that pupil size of $4.50 \mathrm{~mm}$ was used in the current study, and spherical aberration is more affected with larger pupil size $[17,24]$.

There are some factors that need to be considered in this study. Corneal and crystalline lens reflection may hinder the aberration measurement on peripheral retina. This system consists of aperture to reduce such unwanted reflections [25]. Moreover, we checked the signals of each Zernike coefficient and also the wavefront images during the process to assure the correct measurement of ocular aberrations. A limitation of the study may be the measurement of peripheral aberrations with round pupil. An earlier study showed that elliptical transformation is not necessary for eccentricity up to $20^{\circ}$ for the measurement of higher order aberrations [14]. Thu, aberrations on $23^{\circ}$ eccentricity could be better expressed with elliptical transformation. Moreover, in the current study, the head of the subject remained fixed, and the eye moved to fixate peripheral stimulus. During the torsional eye movement, extraocular muscle and lid pressure may affect the shape of globe and hence, 
the aberrations measured with head movement with fixed fixation and eye movement with fixed head may vary. However, Radhakrishnan and Charman did not find any significant difference in peripheral refraction between eye turn and head turn [26]. They concluded that there is no effect of eye turn on peripheral refraction within $30^{\circ}$ of eccentricity and the fixation of less than one minute. In the current study, the fixation duration was less than one minute and peripheral aberration was assessed in less than $30^{\circ}$ off-axis. Therefore, we believe that there was no significant effect of eye torsion on aberrations measured in this study.

\section{Conclusions}

From this study it can be concluded that accommodation affects Zernike coefficients asymmetrically in different peripheral retinal areas. Accommodation reduced the total HOA on superior retina and spherical aberrations on temporal retina but did not affect astigmatism. Higher order astigmatism and spherical aberrations vary from the center to the peripheral retina with accommodation rest, and accommodation helps to reduce this disparity in aberrations. A limited number of studies have investigated the effect of accommodation in higher order aberrations in peripheral retina. Therefore, the findings of this study might be useful in the upcoming investigations related to peripheral higher order aberrations with accommodation. The Zernike coefficients depend on the shape, size and orientation of pupil [17], so the findings of this study should be carefully applied in other cases where the shape, size and orientation of pupil are different. Research with a higher number of subjects with different types of refractive error and the measurement of aberrations on various peripheral eccentricities with higher amount of accommodation stimulation is suggested for the future.

Author Contributions: Conceptualization, K.S., J.G. and S.F.; methodology, K.S., J.G. and S.F.; software, K.S., J.G. and S.F.; validation, S.F.; formal analysis, K.S., J.G. and S.F.; investigation, K.S., J.G. and S.F.; resources, K.S., J.G. and S.F.; data curation, K.S., J.G. and S.F.; writing-original draft preparation, K.S.; writing-review and editing, K.S., J.G. and S.F.; visualization, K.S., J.G. and S.F.; supervision, S.F.; project administration, S.F.; funding acquisition, S.F. All authors have read and agreed to the published version of the manuscript.

Funding: This work was supported by the Portuguese Foundation for Science and Technology (FCT) in the framework of the Strategic Funding UID/FIS/04650/2019 and by the project PTDC/FISOTI/31486/2017 and POCI-01-0145-FEDER-031486. The author Jessica Gomes is also supported by the PhD grant 2020.08737.BD from FCT.

Institutional Review Board Statement: The study was conducted in accordance with the Declaration of Helsinki, and approved by the Ethical Sub-committee of the Life and Health Science of University of Minho (protocol code, SECVS 029/2014 (ADENDA) and date of approval, 2 July 2019).

Informed Consent Statement: Informed consent was obtained from all subjects involved in the study.

Data Availability Statement: Data underlying the results presented in this paper are not publicly available at this time but may be obtained from the authors upon reasonable request.

Acknowledgments: The authors would like to thank Helder Tiago Correia and Sérgio Nascimento for their contribution with the development of the fixation system. They also appreciate the funding support for this work from the FCT.

Conflicts of Interest: The authors declare no conflict of interest. The funders had no role in the design of the study; in the collection, analyses, or interpretation of data; in the writing of the manuscript, or in the decision to publish the results.

\section{References}

1. Zhao, Y.; Fang, F. Nanotechnology and Precision Engineering Measurement of the peripheral aberrations of human eyes: A comprehensive review. Nanotechnol. Precis Eng. 2020, 3, 53-68. [CrossRef]

2. Atchison, D.A.; Scott, D.H.; Charman, W.N. Measuring ocular aberrations in the peripheral visual field using Hartmann-Shack aberrometry. J. Opt. Soc. Am. 2007, 24, 2963-2973. [CrossRef] [PubMed] 
3. Jonas, J.; Schneider, U.; Naumann, G. Count and density of human retinal photoreceptors. Graefe's Arch. Clin. Exp. Ophthalmol. 1992, 230, 505-510. [CrossRef] [PubMed]

4. Lundstrom, L.; Rosen, R.; Baskaran, K. Symmetries in peripheral ocular aberrations. J. Mod. Opt. 2011, 58, 1690-1695. [CrossRef]

5. David, E.; Beitner, J.; Vo, M. The importance of peripheral vision when searching 3D real world scenes A gaze-contingent study in virtual reality. J. Vis. 2021, 21, 3. [CrossRef] [PubMed]

6. Hughes, R.P.J.; Read, S.A.; Collins, M.J.; Vincent, S.J. Higher order aberrations and retinal image quality during short-term accommodation in children. Vis. Res. 2021, 188, 74-84. [CrossRef] [PubMed]

7. Zhou, X.Y.; Wang, L.; Zhou, X.T.; Yu, Z.Q. Wavefront aberration changes caused by a gradient of increasing accommodation stimuli. Eye 2015, 29, 115-121. [CrossRef]

8. Read, S.A.; Buehren, T.; Collins, M.J. Influence of accommodation on the anterior and posterior cornea. J. Cart Refract. Surg. 2007, 33, 1877-1885. [CrossRef]

9. Chen, L.; Kruger, P.B.; Hofer, H.; Singer, B.; Williams, D.R. Accommodation with higher-order monochromatic aberrations corrected with adaptive optics. J. Opt. Soc. Am. 2006, 23, 1-8. [CrossRef]

10. Iida, Y.; Shimizu, K.; Ito, M.; Suzuki, M. Influence of age on ocular wavefront aberration changes with accommodation. J. Refract. Surg. 2008, 24, 696-701.

11. Li, Y.-J.; Choi, J.A.; Kim, H.; Yu, S.-Y.; Joo, C.-K. Changes in ocular wavefront aberrations and retinal image quality with objective accommodation. J. Cart Refract. Surg. 2011, 37, 835-841. [CrossRef] [PubMed]

12. Radhakrishnan, H.; Charman, W.N. Age-related changes in ocular aberrations with accommodation. J. Vis. 2007, 7, 11. [CrossRef] [PubMed]

13. Atchison, D.A.; Scott, D.H. Monochromatic aberrations of human eyes in the horizontal visual field. J. Opt. Soc. Am. 2002, 19, 2180-2184. [CrossRef] [PubMed]

14. Hartwig, A.; Murray, I.; Radhakrishnan, H. Peripheral aberration measurements: Elliptical pupil transformation and variations in horizontal coma across the visual field. Clin. Exp. Optom. 2011, 94, 443-451. [CrossRef]

15. Franco, S.; Gomes, J. Real-Time Measurement of Ocular Wavefront Aberrations in Symptomatic Subjects. Biomed. Res. Int. 2018, 2018, 9415751. [CrossRef]

16. Pugh, J.; Eadie, A.; Winn, B.; Heron, G. Power spectrum analysis in the study of ocular mechanisms. Ophthal. Physiol. Opt. 1987, 7, 321-324. [CrossRef]

17. Lundstrom, L.; Unsbo, P. Transformation of Zernike coefficients: Scaled, translated, and rotated wavefronts with circular and elliptical pupils. J. Opt. Soc. Am. A 2007, 24, 569. [CrossRef]

18. Cheng, H.; Barnett, J.K.; Vilupuru, A.S. A population study on changes in wave aberrations with accomodation. J. Vis. 2004, 4, 272-280. [CrossRef]

19. Atchison, D.A. Higher order aberrations across the horizontal visual field. J. Biomed. Opt. 2006, 11, 034026. [CrossRef]

20. Dubbelman, M.; Van der Heijde, G.L.; Weeber, H.A. Change in shape of the aging human crystalline lens with accommodation. Vision Res. 2005, 45, 117-132. [CrossRef]

21. Mathur, A.; Atchison, D.A.; Charman, W.N. Effect of accommodation on peripheral ocular aberrations. J. Vis. 2009, 9, 20. [CrossRef] [PubMed]

22. Lundstrom, L.; Gustafsson, J.; Unsbo, P. Population distribution of wavefront aberrations in the peripheral human eye. J. Opt. Soc. Am. A 2009, 26, 2192-2198. [CrossRef] [PubMed]

23. Artal, P.; Guirao, A.; Berrio, E.; Williams, D. Compensation of corneal aberrations by the internal optics in the human eye. J. Vis. 2001, 1, 1. [CrossRef] [PubMed]

24. Fan, R.; He, T.; Qiu, Y.; Di, Y.-L.; Xu, S.; Li, Y. Comparison of wavefront aberrations under cycloplegic, scotopic and photopic conditions using WaveScan. Arq. Bras. Oftalmol. 2012, 75, 116-121. [CrossRef] [PubMed]

25. Thibos, L.N.; Hong, X. Clinical Applications of the Shack-Hartmann Aberrometer. Opt. Vis. Sci. 1999, 76, 817-825. [CrossRef] [PubMed]

26. Radhakrishnan, H.; Charman, W.N. Peripheral refraction measurement: Does it matter if one turns the eye or the head? Ophthal Physiol. Opt. 2008, 28, 73-82. [CrossRef] 